\title{
sciendo
}

\section{Costs a pretty penny: how household income impacts upon motorization in Europe and raises manufacturer branding challenges}

\author{
Vlad I. ROȘCA \\ The Bucharest University of Economic Studies, Bucharest, Romania \\ vlad_rsc@yahoo.com
}

\begin{abstract}
This research starts from the findings of a previous study (Roscca, 2018) and intends to develop the preceding statistical model through testing new and more elaborated hypotheses based on the recommendations for future research made in the aforementioned work. The current paper tests demographic and transportation related variables for a multiple regression carried out at a confidence level of 95\%. Regression results show a valid relationship between motorization and the selected regressors. Findings further reveal that motorization rates are most strongly influenced by the gross disposable income of households per capita (H4, $\beta=0.010, p=0.000$ ). Given that three of the demographic and transportation related research hypotheses have not been supported (age, overcrowding, fatalities), it might be argued that motorization should be looked upon more as a market(ing) feat rather than as a social or psychological fact. Car manufacturers should invest more in branding and in market segmentation in order to address the right target groups and properly position themselves with the customers. Branding, hence, becomes important as it creates an emotional connection between the corporate identity of the producers and the image that customers share about it. The closer the brand identity is to the brand image, the more of an impact the brand will have upon customers to spend part of their gross disposable income for car purchases. Starting from the main finding, this article also claims that future research needs to insist more upon the economic determinants of motorization (e.g. inflation, poverty rate, available resources, unemployment rate, interest rate etc.) and to determine their influence on brand preference and car ownership. At the same time, some other demographic variables such as age or generation could be double-checked, as researches provide shattered views upon their role: while some hold them as influential, others subjugate them to the economic determinants.
\end{abstract}

Keywords: motorization; vehicle ownership; household; public transportation; mobility.

\section{Introduction}

This paper intends to continue a research which has revealed that age and generational belonging had an influence on motorization rates in Europe (Roșca, 2018). As the Conclusions section of the aforementioned research revealed, age was only one of the many possible determinants of motorization (p. 60). One of the main limitations of the previous research was that the statistical model has ignored potential regressors such as economic, social or transportation aspects. The low value of the R2 (0.20) for age correlated with motorization has let understand that motorization was a game of two halves, in which, apart from age, other variables had to be taken into account as well. The current paper aims to further develop the regression model, first by including more demographic variables in the 
statistical architecture. Hence, one of the differences from Roșca (2018) will be that the current study will use a multiple regression model as opposed to the previous linear regression. Even if most of the explanatory variables in this study will still be demographic, the paper will also look at traffic volumes or road traffic fatalities as possible variables. Thus, the recommendations from the previous research to include more variables in the model so

as to try and obtain a picture as close to the reality as possible will be followed. Based on the outcomes of this research, the regression model will probably require additional fine-tuning for creating a reliable fit of variable interdependence.

The research is opened by a literature review on motorization which tries to build additional knowledge compared to the literature in the past paper. The review is followed by the hypotheses development and by the methodology, which presents the Research Question and explains how the model is employed. There is also information to be found on data collection and data sampling, similar to the ones from the past research, yet with more observational interplays depending on the degrees of available or missing data. The Discussions section critically analyzes the results of the regression analysis and tests the research hypotheses, while the Conclusions section sums up the investigation by highlighting the key findings and making suggestions for properly developing the model in potential forthcoming studies.

\section{Literature Review}

Motorization is a characteristic of modern lifestyles, especially in affluent societies (Donaghy et al., 2004), determining changes in how household members travel within cities and shaping their transportation habits (Cooper et al., 2005; Hanly, Dargay, 2000; Zacharias, 2005). As such, motorization impacts upon global goals of social interest, such as inclusion, wellbeing and sustainable development (Arpinte, 2010; Cace, 2008; Glăvan, 2010; Prada, 2013; Tomescu, Botonogu, 2011; Trică, Papuc, 2013). Transportation patterns are a prevalent topic of research, especially in what concerns urban areas. In opposition to rural societies, urban spaces are being characterized by an increased level of motorization. Inhabitants of cities and towns have been used to finding an answer to their evergrowing necessities of mobility in vehicle ownership (Choudhary, Vasudevan, 2017). As a consequence, travel modes inside and outside urban areas have been individualized by vehicle possession, with people being able to travel according to their personal needs, at any given times or for any shorter or longer distances, thus enlarging spatial mobility (Frändberg, Vilhelmson, 2011). The desire of vehicle ownership is a spatial dynamic that has become one of the indicators of urban progression which ultimately influences public transport policies (Priemus et al., 2001).

Enlargement of urban spaces and increased commuting distances have created a need for motorization, as a higher mobility is nowadays expected of and desired by people (Cervero, 1996; King, Jacobson, 2017; Sun et al., 2017). Willoughby (2001) defines motorization as the total of advancements made in private car property and use. Car fleet 
volume and motorization rate are directly proportional: on a given market, the more cars are being bought and used, the higher the motorization can be considered. Motorization is expressed as the ratio of total car fleet to total population (Pereira et al., 2017), which results in number of cars per person (Wachnicka, 2017). The European Union measures motorization for statistical purposes as the number of passenger cars per 1,000 people, thus excluding industrial ownership and motorcycles from the equation.

Scientific literature has been preoccupied with studying the determinants of car ownership. Acquisition costs and the economic responsibilities that customers have to endure for owing a vehicle account for most of the differences in motorization rates between distinct geographical areas (Dargay, 2002). Such high investments are justified by the need of higher mobility and dynamics in transportation (Dargay, Vythoulkas, 1999), nevertheless, they can only be made if the necessary income is available (Nolan, 2010). Therefore, most research regards vehicle acquisition as a household decision, and not as an individual decision (Clark, 2009). Car purchases are thus portrayed as high-involvement decisions (Molesworth, Surotti, 2002): first, much information about the product is collected before making the final decision (Cai et al., 2004) and, second, usually, all or most of the household members are involved in the call (Oliver, Lee, 2010). The types of information to be collected might be as diverse as possible. This work further concentrates on four items of potential information (variables) that might influence vehicle acquisition in order to develop the research hypotheses.

\section{Hypotheses Development}

The importance of statistical models in determining transport and motorization patterns has been acknowledged for a while now (Mannering \& Hensher, 1987; Van Wissen \& Meurs, 1989). Numerous studies have investigated the relationship between economic growth and motorization (Al-Reesi et al., 2013). Economic development leaves its mark upon transportation habits and the needs of people (Bell et al., 2002; Cooper et al., 2005; Hanly, Dargay, 2000; Zacharias, 2005) or upon the availability and quality of public transport policies (Priemus et al., 2001), which ultimately influence motorization rates. The latter ones, though, are impacted by a considerable set of other factors. This paper looks at four of them (age, overcrowding, number of road accidents fatalities, gross disposable income) in order to assert their impact upon motorization.

The Null Hypothesis $\left(\mathrm{H}_{0}\right)$ claims that there is no significant correlation between motorization and the independent variables. The following four hypotheses have been developed:

H1: Age positively influences motorization: Gallez (1994) makes a point that motorization is influenced by age. He brings into discussion a behavioristic pattern identified among people of 'middle age' in life, who influence multi-motorization (multiple vehicle ownership per person). Gallez claims that this trend is identifiable among people heading towards or even past the middle of their life expectancy. This argument is supported by 
findings of Dargay and Vythoulkas (1999), who show that a peak in vehicle ownership is identifiable around the age segment of 50 years. Prior to the age of 50 the available income to invest in more than one car is rather low. Around 50, people have higher savings accumulated through life, which now allow them to invest in extra cars. At the same time, the need for multiple car ownership becomes higher around that age, since the number of driving license owners in the household expands: i.e. children now obtain their driving license and more than one car is needed for mobility in the family, a fact that leads to a constant dynamic of family structures (Stanciu, 2016). Then, after 50 years of age, car purchases tend to diminish due to lower needs of mobility and also lower income (both strongly influenced by retirement). By combining the findings of the two researches, it can be argued that much of the motorization levels are being driven by people aged 35 to 50 , thus past their young hood and prior to their adulthood.

H2: Overcrowding / traffic flow, overpopulation / traffic composition negatively influences motorization: In many third world countries, traffic composition is a fusion of fast-moving, motorized vehicles and slow-moving, human or animal propelled vehicles (Khan, Maini, 1999). Such settings, where non-motorized vehicles can account for even more than half of transportation distances covered, lead to massive overcrowdings. For most of Europe, this picture is already history, yet traffic congestions influenced by a high volume of car fleet and improper traffic management and conditions are nothing strange. Moreover, overcrowding - rate of people living in an area with population in excess - can leave its marks on traffic flows and people's decision to use a car or not. The higher the overcrowding, the higher also the traffic congestions, which might determine people to give up using private cars for the sake of alternative or public transportation methods.

H3: People killed in road accidents negatively influences motorization: The relationship between motorization and the number of people killed in road accidents might just seem obvious, with Evans (1991) and Kopits and Cropper (2005) claiming that, if the vehicle fleet increases, the number of traffic fatalities might worsen. Neither Evans, nor Kopits and Cropper do not make a conclusive statement that fatality risk has to automatically increase with motorization, but most other research findings support a directly proportional relationship between increasing motorization and road traffic injuries, or even deaths (Gururaj, 2008; Naghavi et al., 2009). Zhang et al. (2017) confirm that the number of fatalities can be predicted by motorization levels, yet technological and cultural factors also have to be taken into consideration if researching fatalities. Among the same lines, Soehodho (2007) identifies a connection between motorization and the number of fatal accidents, but highlights that motorization alone cannot be blamed. Instead, motorization-related decisions such as traffic control and traffic management have to be considered. Since road accidents are one of the most reoccurring transportation-related risk factors (Jiang et al., 2017), it would be important to know if this risk might have any influence on people's perceptions, which could translate in reduced motorization rates. 
H4: Gross disposable income of households per capita positively influences motorization: As with most other goods in the economy, the chances of vehicle acquisition increase once with income. Considering that car ownership is a complex buying decision, Dargay (2001) finds out that there is a stronger response to rising income than to falling income. People will not start irrational behavior if the available income drops, but will probably take the purchase of a car more seriously into consideration if they can document a stable rise in income.

\section{Methodology}

While motorization has got an impact upon public transportation, there is still an open question as to what drives motorization itself. Motorization can be a result of many factors, among which demographic, economic, technological, political, cultural or social ones. The objective of this research is to analyze statistical data provided by Eurostat for determining several possible influences on motorization rate, mainly demographical and transportation (behavioral). The Research Question asks: How is motorization influenced by demographic and behavioral variables?

A multiple regression was carried out in order to identify the effects of several independent variables on the rate of motorization. The regression formula employed was:

\section{$Y_{R m o t}=f\left\{\alpha+\beta_{1}[\right.$ Median Age $]+\beta_{2}\left[\right.$ Overcrowding] $+\beta_{3}[$ People killed in road accidents] $+\beta_{4}$ [Gross disposable income of households per capita (Purchasing Power Standard) $]\}+\varepsilon$}

where $Y_{\text {Rmot }}$ represents the rate of motorization, expressed as 'Cars per 1000 inhabitants" and selected as the dependent variable $(y)$ is a function of $\alpha=$ intercept value; $\beta 1 \ldots \beta 4=$ the coefficients of the independent variables $\mathrm{x}$ to be estimated; $\varepsilon=$ the error term, while [Median age], [Overcrowding], [People killed in road accidents] and [Gross disposable income of households per capita (Purchasing Power Standard)] are the independent variables $(x)$.

A desk research has been carried out with secondary data from Eurostat. The study took a longitudinal form, with data being collected for the interval 2008-2015 ( $t=8$ years) for 22 European countries ( $q=22$ : Belgium, Czech Republic, Germany, Estonia, Ireland, Greece, Spain, France, Italy, Cyprus, Latvia, Luxembourg, Hungary, The Netherlands, Austria, Poland, Romania, Slovenia, Finland, Sweden, Norway, Switzerland). The experimental cycle was set at $t=8$ and $q=22$ for fending off any likely short-term proxies that might wield pressure on results. Dependent and predictor variable values were collected for all 22 countries observed. From the total potential of 176 observations, seven have been removed due to incomplete statistical data: Ireland 2014, 2015 (no data for people killed in road accidents), France 2008 (cars/1000 inhabitants), Italy 2015 (cars/1000 inhabitants), Netherlands 2014, 2015 (cars/1000 inhabitants), Sweden 2015 (people killed in road accidents). The other 169 
observations were valid and have been introduced into the regression $(n=169)$. The regression was conducted at a confidence level of 0.95 .

\section{Results and discussions}

An ANOVA Single Factor Analysis $(\alpha=0.05)$ has been used to test the Null Hypothesis. The outcomes in Table 1 reveal a greater value of $F$ than the Fcritical $(1708.24>2.38)$ as well as a P-Value lower than the critical alpha value $(0.00<0.05)$, which proves good evidence for rejecting $\mathrm{H}_{0}$ for the good of the Alternative Hypothesis: the motorization rate is influenced by the dependent variables $(\mathrm{y})$.

Table 1. Anova Single Factor Analysis

\begin{tabular}{|ccccccc|}
\hline Source of Variation & SS & $d f$ & $M S$ & $F$ & P-value & Fcrit \\
\hline \hline Between Groups & 50011065898 & 4 & 12502766474 & 1708.24 & 0.000 & 2.38253 \\
Within Groups & 6148035910 & 840 & 7319090.369 & & & \\
Total & 56159101807 & 844 & & & & \\
\hline
\end{tabular}

Source: Authors' own research based on statistical data inputs collected from Eurostat.

The regression model using the independent variables [Median Age], [Overcrowding], [People Killed in Road Accidents] and [Gross disposable income of households per capita] explains $54 \%$ of the variance in Motorization (R Square $=0.54$ ). The Multiple R value (.73) indicates a medium to strong relationship between the variables. The effects of the independent variables on motorization are described in Table 2, with the Standard Errors displayed within parentheses.

Table 2. Effects Of The Independent Variables On Motorization

\begin{tabular}{|c|c|c|}
\hline \multirow{3}{*}{$\begin{array}{l}\text { Intercept } \\
\text { Variables }\end{array}$} & \multirow{3}{*}{$235.09(94.30)$} & P-Value \\
\hline & & 0.013664599 \\
\hline & & \\
\hline Median Age & $1.30(2.45)$ & 0.595452969 \\
\hline Overcrowding & $-0.83(0.46)$ & 0.074662454 \\
\hline People Killed in & & \\
\hline Road Accidents & $0.005(0.003)$ & 0.168735664 \\
\hline $\begin{array}{l}\text { Gross disposable income } \\
\text { of households per capita }\end{array}$ & $0.01(0.001)$ & 0.000000000000500699561 \\
\hline
\end{tabular}

Source: Authors' own research based on statistical data inputs collected from Eurostat.

The regression is statistically significant at a Sig-F level of 9.51x10-27 $<\alpha=0.05$ (Sig$\mathrm{F}=0.000000000000000000000000009518)$. The intercept parameter $(\alpha=235.09)$ indicates 
that, considering all independent variables were equal to zero, 235 cars per 1000 inhabitants would exist. The predictor variables are strongly and positively related to the $\mathrm{x}$-variable, which is expressed by the correlation coefficient $R=0.735$. Nevertheless, the regression analysis shows (Table 3 ) that the only determinant of all the selected independent variables which can really have an influence on the rhythm of motorization is the gross disposable income of households (P-value $=0.00<\alpha=0.05$ ).

Table 3. Regression Values for Hypothesis Testing

\begin{tabular}{|c|c|c|c|c|}
\hline Hypothesis & Variable & $\boldsymbol{\beta}$ & Probability & Supported \\
\hline $\mathrm{H}_{1}$ & Age & 1.305 & 0.595 & NO \\
\hline $\mathrm{H}_{2}$ & Overcrowding & -0.835 & 0.074 & NO \\
\hline $\mathrm{H}_{3}$ & People killed in road accidents & 0.005 & 0.168 & NO \\
\hline $\mathrm{H}_{4}$ & Gross disposable income of households/capita & 0.010 & 0.000 & YES \\
\hline
\end{tabular}

Source: Authors' own research based on statistical data inputs collected from Eurostat.

Each unit increase in gross disposable income translates in a 0.01 unit increase in motorization. One hundred unit increases in gross disposable income are necessary for one extra car per 1000 people. The other three variables are not statistically relevant due to their P-Value greater than 0.05 .

Research results show that the only hypothesis which stands as true is $\mathrm{H} 4$ concerning the gross disposable household income. Given that the purchase of a vehicle is a complex economic decision, the available budget of a household outclasses other factors. The research indicates that the purchase of a car is, first and foremost, a matter of having the money to pay for the good, not an instance of demographic variables such as age (Bărbulescu, 2010, 2012; Istrate, 2015; Stanciu, Mihăilescu, 2018) or of psychological aspects like the fear of being involved in an accident or having to deal with overcrowding in traffic. The results of this research are backed up by De Jong et al. (2004), who demonstrated that car ownership is modelled by household income and by Clark (2007) who shows that the number of cars that a household owns depends on income. The two variables are in a directly proportional relationship: the higher the income, the greater the car ownership (Dargay, 2001). Even if a household has a need for a car, if the money is not available, the need will only persist. Nolan (2010) found income to be the most influential determinant of car ownership, also making a relevant distinction between permanent income and current income: what a household needs for investing in the purchase of a car is a long-term available income rather than brief spells of income increases that cannot support savings.

It can be argued that the purchase of a vehicle that would ultimately drive to higher motorization rates is largely depending on financial aspects (Chatterton et al., 2018). Motorization is thus impacted by a financial purchase decision rather than an emotional one (accidents, overcrowding etc.). He and Thøgersen (2017) differentiate between the attitude towards buying a car and the actual purchase: the authors believe that, even if the intention 
to purchase a car exists, if this is not backed up by situational factors such as having the right money at the right time, then no movements will be felt on the market.

This study contradicts the findings of Roșca's (2018) previous research to the extent that it is now revealed that age does not have an impact on motorization. Nevertheless, several authors have indicated that age had an influence on motorization (Gallez, 1994; Klein and Smart, 2017), yet, probably, not at a full extent. When combined with other regressors, age loses its influence, explaining some part of motorization rates, though not all of it. For example, Klein and Smart (2017) find out that people born during the 1980's and 1990's own less cars than their parents did at their age. However, this is not a matter of merely being young or adult or of the transportation habits that might have changed over the years, but of the fact that young people nowadays accumulate wealth slower than their parents did. In the end, it all comes down to having the money to pay for a new car, which Millennials nowadays mostly do not have. Their lack of economic independence makes many youngsters still live with their parents and, as a consequence, share the car of the household. The youngsters' standard of living has to improve in order for them to hope for buying a car (Al-Reesi, 2013) and, even so, purchasing a vehicle seems not to be the easiest of acquisitions, given that for one additional car to one thousand people, an extra of one hundred increases in gross disposable income is needed.

\section{Conclusion and Future Research}

Motorization is a characteristic of modern societies, affecting not only lifestyles, but also markets (Colditz, 1999; Meschik, 2012). This study offers comprehension about some of the drivers of motorization. The results uphold findings of Clark (2007), Dargay (2001, 2002) and De Jong et al. (2004), who all insisted that motorization was mainly affected by economic variables like available income or acquisition and maintenance costs. Given that three of the demographic and transportation related research hypotheses have not been supported (age, overcrowding, fatalities), it might be argued that motorization should be looked upon more as a market(ing) feat rather than as a social or psychological fact. The fact that overcrowding, age and road fatalities do not play a significant role, but, instead, the available income does, leads to the conclusion that car manufacturers should invest more in branding and in market segmentation in order to address the right target groups and properly position themselves with the customers. Semiotics, in this case (the messages and signals that a brand conveys), might assist the sales opportunities, especially when delivered via the proper media channels, since it can lead to the creation of proper media models (Drămnescu, Enăchescu, 2018; Enăchescu, Tarabay, 2016; Negrea, Voinea, 2018; Smarandache et al., 2019; Vlăduțescu, 2018a, 2018b, 2019). These facts tend to be accelerated by the digitalizaion of contemporary media (Ignat et al., 2019). Manufacturer brands can therefore opt for digital storytelling to share their values with the target groups (Gregori-Signes, Alcantud-Díaz, 2016; Militello, Guajardo, 2013; Tello-Leal et al., 2012). 
Therefore, future research needs to insist more upon the economic determinants of motorization (e.g. inflation, poverty rate, available resources, unemployment rate, interest rate etc.) and to determine their influence on brand preference and car ownership. At the same time, some other demographic variables such as age or generation could be doublechecked, as researches provide shattered views upon their role: while some hold them as influential, others subjugate them to the economic determinants.

In what concerns the limitation of this research, even if the regression equation has been extended from a bivariate to a multivariate linear model, it still neglected many possible determinants of motorization, focusing on only four variables that were more or less connected to each other. This simplistic view might have left many potential findings uncovered, just as the rather frail observations number $(n=169)$ might have done. For more profoundness, other studies might try to extend the observational interval. The data for the study has been collected from 22 European countries characterized by different economic development speeds. A potential danger upon the validity of the results might be that car acquisition decisions differ between countries because of different level of income and growth. One way to test if the results of this research are reliable is to check the model, yet applied to either one country at a time, or to regional clusters (e.g. the Balkans, Central Europe, and Western Europe).

Overall, this paper tries to bring about more insights about motorization, a distinguishing trait of modern economies that can only be expected to leave its marks further on in future years, given the meaningful roles that transportation, mobility and sustainability play on political agendas nowadays (Acharya, 2005; Alpopi, Colesca, 2010; Alpopi et al., 2011; Bugheanu, Colesca, 2016; Colesca et al., 2017).

\section{References}

Acharya, S. R. (2005). Motorization and urban mobility in developing countries exploring policy options through dynamic simulation. Journal of the Eastern Asia Society for Transportation Studies, 6, 4113-4128.

Alpopi, C., \& Colesca, S. E. (2010). Urban air quality. A comparative study of major European capitals. Theoretical and Empirical Researches in Urban Management, 15, 92-107.

Alpopi, C., Manole, C., \& Colesca, S. E. (2011). Assessment of the sustainable urban development level through the use of indicators of sustainability. Theoretical and Empirical Researches in Urban Management, 6(2), 78-87.

Al-Reesi, H., Ganguly, S. S., Al-Adawi, S., Laflamme, L., Hasselberg, M., \& Al-Maniri, A. (2013). Economic growth, motorization, and road traffic injuries in the Sultanate of Oman, 1985-2009. Traffic Injury Prevention, 14(3), 322-328.

Arpinte, D. (2010). Social Economy in Teleorman County. Journal of Community Positive Practices, 10(1-2), 72-81.

Bărbulescu, R. (2010). Risks and consequences of demographic changes in Romania. The Romanian Economic Journal, 36, 99-110. 
Bărbulescu, R. (2012). Romania's demographic decline-what's next. Romanian Economic and Business Review, 7(2), 77-86.

Bell, A. C., Ge, K., \& Popkin, B. M. (2002). The road to obesity or the path to prevention: motorized transportation and obesity in China. Obesity, 10(4), 277-283.

Bugheanu, A. M., \& Colesca, S. E. (2016). Empirical Research on Urban Public Transportation in the Context of Population Growth and the Demographic Development. Management and Economics Review, 1(2), 183-193.

Cace, S. (2008). Social Inclusion at the Level of the European Union. Journal of Community Positive Practices, 8(3-4), 21-33.

Cai, L. A., Feng, R., \& Breiter, D. (2004). Tourist purchase decision involvement and information preferences. Journal of Vacation Marketing, 10(2), 138-148.

Cervero, R. (1996). Mixed land-uses and commuting: evidence from the American Housing Survey. Transportation Research Part A: Policy and Practice, 30(5), 361-377.

Chatterton, T., Anable, J., Cairns, S., \& Wilson, R. E. (2018). Financial Implications of Car Ownership and Use: a distributional analysis based on observed spatial variance considering income and domestic energy costs. Transport Policy, 65, 30-39.

Choudhary, R., \& Vasudevan, V. (2017). Study of vehicle ownership for urban and rural households in India. Journal of Transport Geography, 58, 52-58.

Clark, S. D. (2007). Estimating local car ownership models. Journal of Transport Geography, 15(3), 184-197.

Clark, S. D. (2009). The determinants of car ownership in England and Wales from anonymous 2001 census data. Transportation Research Part C: Emerging Technologies, $17(5), 526-540$.

Colditz, G. A. (1999). Economic costs of obesity and inactivity. Medicine and Science in Sports and Exercise, 31(11 Suppl), S663-7.

Colesca, S. E., Pacesila, M., Burcea, S. G., Ciocoiu, C. N., \& Bugheanu, A. M. (2017). Analysis Of Passenger's Satisfaction With The Quality Of The Public Transportation Mode Choices In Bucharest: A Fuzzy Approach. Economic Computation \& Economic Cybernetics Studies \& Research, 51(4), 109-125.

Cooper, A. R., Andersen, L. B., Wedderkopp, N., Page, A. S., \& Froberg, K. (2005). Physical activity levels of children who walk, cycle, or are driven to school. American Journal of Preventive Medicine, 29(3), 179-184.

Dargay, J. M., \& Vythoulkas, P. C. (1999). Estimation of a dynamic car ownership model: a pseudo-panel approach. Journal of Transport Economics and Policy, 287-301.

Dargay, J. M. (2001). The effect of income on car ownership: evidence of asymmetry. Transportation Research Part A: Policy and Practice, 35(9), 807-821.

Dargay, J. M. (2002). Determinants of car ownership in rural and urban areas: a pseudo-panel analysis. Transportation Research Part E: Logistics and Transportation Review, 38(5), 351-366. 
De Jong, G., Fox, J., Daly, A., Pieters, M., \& Smit, R. (2004). Comparison of car ownership models. Transport Reviews, 24(4), 379-408.

Donaghy, K., Rudinger, G., \& Poppelreuter, S. (2004). Societal trends, mobility behaviour and sustainable transport in Europe and North America. Transport Reviews, 24(6), 679690.

Drămnescu, M., \& Enăchescu, V. (2018). The Role of Models Promoted through the Media in the Build of Personality. In The International Scientific Conference eLearning and Software for Education, Vol. 1, 86-94. "Carol I" National Defence University.

Enăchescu, V.A., \& Tarabay, D. (2016). Internet is Changing Cultures. Revista de Management Comparat International, 17(3), 272-278.

Evans, L. (1991). Traffic Safety and the Driver. Science Serving Society. New York: Van Nostrand Reinhold Co.

Frändberg, L., \& Vilhelmson, B. (2011). More or less travel: personal mobility trends in the Swedish population focusing gender and cohort. Journal of Transport Geography, 19(6), 1235-1244.

Gallez, C. (1994). Identifying the long term dynamics of car ownership: a demographic approach. Transport Reviews, 14(1), 83-102.

Glăvan, E. (2010). Social Economy in Mehedinti County. Journal of Community Positive Practices, 10(1-2), 28-61.

Gregori-Signes, C., \& Alcantud-Díaz, M. (2016). Digital community storytelling as a sociopolitical critical device. Journal of Community Positive Practices, 16(1), 19-36.

Gururaj, G. (2008). Road traffic deaths, injuries and disabilities in India: current scenario. National Medical Journal of India, 21(1), 14-20.

Hanly, M., \& Dargay, J. (2000). Car ownership in Great Britain: Panel data analysis. Transportation Research Record: Journal of the Transportation Research Board, (1718), 83-89.

He, S. Y., \& Thøgersen, J. (2017). The impact of attitudes and perceptions on travel mode choice and car ownership in a Chinese megacity: The case of Guangzhou. Research in Transportation Economics, 62, 57-67.

Ignat, R., Trică, C. L., \& Tudor, M. (2019). Opportunities for Romanian Entrepreneurs in Digital Single Market. Ovidius University Annals, Economic Sciences Series, 19(1), 202-208.

Istrate, M. I. (2015). Urban sprawl and demographic dynamics in Suceava Metropolitan Area. Journal of Community Positive Practices, 15(2), 43-55.

Jiang, B., Liang, S., Peng, Z.R., Cong, H., Levy, M., Cheng, Q., Wang, T. \& Remais, J. V. (2017). Transport and public health in China: the road to a healthy future. The Lancet, 390(10104), 1781-1791.

Khan, S., \& Maini, P. (1999). Modeling heterogeneous traffic flow. Transportation Research Record: Journal of the Transportation Research Board, (1678), 234-241.

King, D. M., \& Jacobson, S. H. (2017). What is driving obesity? A review on the connections between obesity and motorized transportation. Current Obesity Reports, 6(1), 3-9. 
Klein, N. J., \& Smart, M. J. (2017). Millennials and car ownership: Less money, fewer cars. Transport Policy, 53, 20-29.

Kopits, E., \& Cropper, M. (2005). Traffic fatalities and economic growth. Accident Analysis \& Prevention, 37(1), 169-178.

Mannering, F., \& Hensher, D. A. (1987). Discrete/continuous econometric models and their application to transport analysis. Transport Reviews, 7(3), 227-244.

PICBE | 770

Meschik, M. (2012). Reshaping city traffic towards sustainability Why transport policy should favor the bicycle instead of car traffic. Procedia-Social and Behavioral Sciences, 48, 495504.

Militello, M., \& Guajardo, F. (2013). Virtually speaking: How digital storytelling can facilitate organizational learning. Journal of Community Positive Practices, 13(2), 80-91.

Molesworth, M., \& Suortti, J. P. (2002). Buying cars online: the adoption of the web for highinvolvement, high-cost purchases. Journal of Consumer Behaviour: An International Research Review, 2(2), 155-168.

Naghavi, M., Shahraz, S., Bhalla, K., Jafari, N., Pourmalek, F., Bartels, D., Puthenpurakal, J.A. \& Motlagh, M.E. (2009). Adverse health outcomes of road traffic injuries in Iran after rapid motorization. Archives of Iranian Medicine, 12(3), 284-294.

Negrea, X., \& Voinea, D. V. (2018). Procedures, Rituals And Creativity In The Mediatic Text. Social Sciences and Education Research Review, 5(2), 124-132.

Nolan, A. (2010). A dynamic analysis of household car ownership. Transportation Research Part A: Policy and Practice, 44(6), 446-455.

Oliver, J. D., \& Lee, S. H. (2010). Hybrid car purchase intentions: a cross-cultural analysis. Journal of Consumer Marketing, 27(2), 96-103.

Pereira, B. B., da Cunha, P. B., Silva, G. G., de Campos Júnior, E. O., Morelli, S., Vieira Filho, C. A., Pereira de Lima, E.A. \& Barrozo, M. A. S. (2017). Integrated monitoring for environmental health impact assessment related to the genotoxic effects of vehicular pollution in Uberlândia, Brazil. Environmental Science and Pollution Research, 24(3), 2572-2577.

Prada, E.M. (2013). Economic development and migration in European Union. Ovidius University Annals, Economic Sciences Series, 13(1), 259-264.

Priemus, H., Nijkamp, P., \& Banister, D. (2001). Mobility and spatial dynamics: an uneasy relationship. Journal of Transport Geography, 9(3), 167-171.

Roșca, V.I. (2018). Too young to drive? The impact of age and generational cohorts on motorization in Europe. Theoretical and Empirical Researches in Urban Management, 13(2), 53-64.

Smarandache, F., Colhon, M., Vlăduțescu, Ş., \& Negrea, X. (2019). Word-level neutrosophic sentiment similarity. Applied Soft Computing, 80, 167-176.

Soehodho, S. (2007). Motorization in Indonesia and its impact to traffic accidents. IATSS Research, 31(2), 27-33. 
Stanciu, M. (2016). Evolution Of The Family Structures In Romania. Journal of Community Positive Practices, 16(4), 80-100.

Stanciu, M., \& Mihăilescu, A. (2018). Population Dynamics in Romania during the Last Century. 1918-2017. Journal of Community Positive Practices, 18(1), 37-46.

Sun, B., Ermagun, A., \& Dan, B. (2017). Built environmental impacts on commuting mode choice and distance: Evidence from Shanghai. Transportation Research Part D: Transport and Environment, 52, 441-453.

Tello-Leal, E., Sosa-Reyna, C. M., \& Tello-Leal, D. A. (2012). The digital divide: ICT development indices in Mexico. Journal of Community Positive Practices, 4(3), 797-811.

Tomescu, C., Botonogu, F. (2011). The Roma: Inclusion Through Social Economy. Journal of Community Positive Practices, 11(1), 93-111.

Trică, C.L., \& Papuc, M. (2013). Green economic growth premise for sustainable development. Theoretical and Applied Economics, 18(1/(578)), 131-140.

Van Wissen, L. J. G., \& Meurs, H. J. (1989). The Dutch mobility panel: Experiences and evaluation. Transportation, 16(2), 99-119.

Vlăduțescu, Ş. (2018a). The Implied Message. Social Sciences and Education Research Review, 5(1), 203-209.

Vlăduțescu, S. (2018b). Six Steps of Hermeneutical Process at H.-G. Gadamer. Postmodern Openings, (2), 161-174.

Vlăduțescu, Ș. (2019). Messages and signals. Social Sciences and Education Research Review, 6(1), 170-176.

Wachnicka, J. (2017). Modelling fatalities on regional road networks. In MATEC Web of Conferences, Gambit 2016, Vol. 122, 03011, 1-6. EDP Sciences.

Willoughby, C. (2001). Singapore's motorization policies 1960-2000. Transport Policy, 8(2), 125-139.

Zacharias, J. (2005). Non-motorized transportation in four Shanghai districts. International Planning Studies, 10(3-4), 323-340.

Zhang, J., Garrick, N. W., Atkinson-Palombo, C., \& Ahangari, H. (2017). How similar is China's traffic safety pattern to industrialized countries in their early stage of motorization? An analysis of death registration data for large and small/medium cities. Journal of Transportation Safety \& Security, 9(sup1), 83-102. 